Article

\title{
A Creative Living Lab for the Adaptive Reuse of the Morticelli Church: The SSMOLL Project
}

\author{
Maria Cerreta ${ }^{1, *(\mathbb{D})}$, Alessia Elefante ${ }^{2}$ and Ludovica La Rocca ${ }^{1}$ (D) \\ 1 Department of Architecture (DiARC), Federico II University of Naples, 80134 Naples, Italy; \\ ludovica.larocca@unina.it \\ 2 Urban Regeneration and Social Innovations, Blam, 84133 Salerno, Italy; info@blamteam.com \\ * Correspondence: maria.cerreta@unina.it
}

Received: 2 November 2020; Accepted: 14 December 2020; Published: 17 December 2020

\begin{abstract}
The international debate on the adaptive reuse of cultural heritage sites consistent with the Sustainable Development Goals has become increasingly important in the implementation of circular economy models for urban policies. The new values that characterize cultural assets, considered the result of a collaborative process, can enhance both manufactured and human capital, and provide the basis for a system of relationships that binds them. Furthermore, the values of historical artistic assets produced by community-based regeneration processes are particularly relevant when they characterize abandoned commons and cult buildings, to which communities attribute an identity and symbolic value. Starting from the definition of the concept of complex social value, we propose a methodological process that combines approaches and techniques typical of deliberative evaluations and collaborative decision-making processes. The aim is to identify the complex value chains generated by adaptive reuse, in which intrinsic values can play a driving role in the regeneration strategies of discarded cultural heritage. The experimentation, tested with the project "San Sebastiano del Monte dei Morti Living Lab" (SSMOLL), activates a creative and cultural Living Lab in the former Morticelli church, in the historic center of Salerno, in southern Italy. The reuse project is part of a more comprehensive process of social innovation and culture-led urban regeneration triggered in Salerno starting from SSMOLL. The partial results of the process show how a co-exploration phase has characterized the cultural characteristic of the living lab and how the co-evaluation of the individual activities orient the possible reuse scenarios. Finally, the results provide a first analysis of the relationship types activated.
\end{abstract}

Keywords: cultural heritage; adaptive reuse; urban regeneration; community-based approach; culture-driven innovation; collaborative decision-making process; co-evaluation; intrinsic value

\section{Introduction}

Within the national and international debate on the future of cities, community and identity, cultural heritage plays a decisive role in their interpretation and transformation. The eleventh Sustainable Development Goal notes that, at a global level, urban areas are expanding at a faster pace than their populations. Between 2000 and 2014, the areas occupied by cities grew 1.28 times faster than their populations [1]. Thus, urban density in cities has decreased, resulting in profound repercussions for environmental sustainability [2] and affecting the continuously declining cultural heritage $(\mathrm{CH})$.

The European Commission (EC) defines cities as favorable environments for culture-driven innovation both because of the greater local autonomy that characterizes them and because of the attention given to the needs and potential of their inhabitants. Therefore, the EC encourages the activation of participatory processes to safeguard abandoned $\mathrm{CH}$, interpreted as a strategic resource for sustainable development [3,4]. In this perspective, the establishment of the heritage community [5] is central to new urban policies in which cultural heritage is the main driver of urban development. 
$\mathrm{CH}$ is a shared resource that can strengthen a common identity and positively influence people's quality of life $[5,6]$. Seventy-one percent of Europeans agree that "living near heritage sites can improve quality of life", and up to $84 \%$ of Europeans think that $\mathrm{CH}$ is as essential at a personal level as it is for the local community [7].

The European Year of $\mathrm{CH}, 2018$, prompted a reflection on heritage and concrete opportunities for reuse of public cultural heritage. A particularly lively debate defines "adaptive" reuse of these places [8-11] as a powerful strategy to manage the change of the state of a building through a more comprehensive process of social regeneration and urban sustainability [12]. The adaptive reuse process occurs when, between the decommissioning and reuse of assets, the designed strategy uses and develops methods to assess the compatibility of new functions with the architectural features of buildings [13,14].

A lack of public resources has increasingly pushed local governments to support processes of adaptive reuse of historic assets and to experiment with new cultural experiences and social cohesion, new forms of cultural enterprises and active citizenship, and models of governance shared with local profit/non-profit realities. The reactivation of these places is, therefore, often connected to the implementation of hybrid creative processes, capable of generating new forms of vitality, creative urban productivity, and social and economic innovation, involving young professionals, artists, researchers, weaker segments of the community, migrants, and the unemployed [15-17].

Within urban contexts, adaptive reuse of $\mathrm{CH}$ thus plays a decisive role in terms of environmental sustainability, while at the same time producing multidimensional benefits: cultural benefits (keeping "alive" a symbol of community identity), economic benefits (in terms of increased productivity), environmental benefits (such as reduced consumption of non-renewable resources), and social benefits (such as increased employment) [18-20]. In the processes of adaptive reuse, the transition from "waste places" to "catalytic places" of new opportunities is included in the new dynamics of the urban circular economy [21-24], characterized not only by the recovery of the manufactured capital but mostly by the enhancement of the human capital involved in the process.

In the panorama of the abandoned cultural sites, churches represent a widespread network of assets at the international level and religious $\mathrm{CH}$, on the whole, constitutes the most frequent category that characterizes UNESCO sites. Since 2015, in Europe, data reflect an increasing number of buildings abandoned by the Catholic Church. According to a survey developed in 2015 [25], about twenty churches are closed each year in England, and about three hundred churches are abandoned or semi-abandoned in Denmark. In the Netherlands, the tendency to abandon holy places is rapidly increasing: the Dutch Catholic Church estimates that two-thirds of its 1600 churches will be abandoned by 2025, and 700 Dutch Protestant churches will be closed by 2021 .

In Italy, churches constitute the most recurrent territorial infrastructure of the landscape: the census of dioceses counts about 66,930 buildings, owned by 219 Italian dioceses; buildings of religious orders and the more than 800 churches of the Ministry of Interior's Worship (Fec) are excluded [26]. The total number of actual churches is thought to be two or three times greater than the census figure. Notably, this total still excludes the large number of other religious buildings, such as convents, monasteries, libraries, museums, and archives, that constitute a large part of the Italian building heritage [27]. Although defining the size of the religious heritage is a complex undertaking, ascertaining the conditions of this heritage is even more challenging.

In 2014, Future for Religious Heritage (FRH), in collaboration with Sociovision, carried out a survey aimed at investigating the relationships of European citizens with former churches and other religious buildings, involving 6000 citizens from 8 European countries [28]. A convincing majority agreed that religious heritage represents a unique and essential part of cultural heritage and is a crucial component of European identity (Figure 1). 


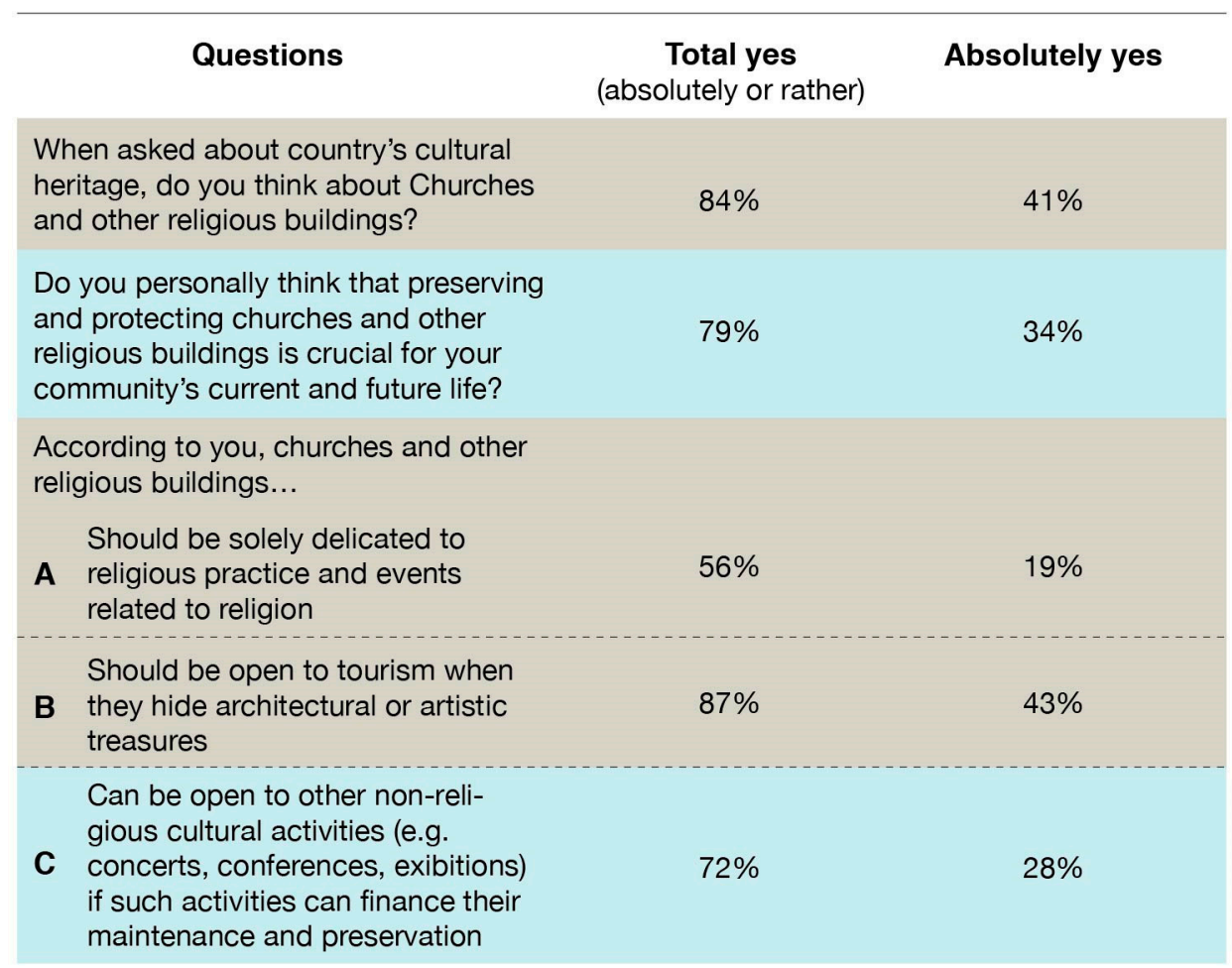

Figure 1. Data extracted from the Future for Religious Heritage (FRH) and Sociovision survey, 2014.

The results of the survey show how religious goods still play a crucial role in the life of contemporary cities [25] and how they are considered special because of their cultural and social importance, with high spiritual significance that binds them to the territory and the local community [29].

The adaptive reuse of locations of $\mathrm{CH}$ represents a precious opportunity to generate new values and, in particular, complex social values [30,31], characterized both by the economic component expressed by the total economic value, and by the non-economic component, constituted by the intrinsic value. It can also guide the valuation processes in the identification of new ways of reuse to preserve and hand down the tangible and intangible values of $\mathrm{CH}$. It is possible to highlight how, for places of $\mathrm{CH}$, the immaterial component attributable to the intrinsic value [31-33] is particularly relevant from an adaptive reuse perspective.

As an architectural artefact produced by humans for humans, in addition to having an anthropocentric instrumental value that recognizes its ability to satisfy human needs, $\mathrm{CH}$ also possesses an anthropocentric intrinsic value, recognizing that it possesses an inherent interest. In addition to economic benefits, it is therefore also recognized as a value independent of use and dependent on its existence, its symbolic meaning, its architectural features, its role in history [34].

The intrinsic value is strictly connected to the autopoietic capacity [35] of the cultural heritage to regenerate its nature through the anthropic action of preservation and reuse, and specifically through the expression of "glue value", that is, the set of those relational values able to build bonds and generate new values: social, cultural, and economic. Precisely because of their ability to generate new economies, the intrinsic values appropriate to the $\mathrm{CH}$ become driving forces in the strategies of valorization and determinants in the strategic choices that characterize the territories.

The decision-making process becomes, therefore, crucial to address holistically the different components at stake: values and meanings of the abandoned heritage, physical characteristics and potential of the asset [36,37], and context and heritage community [5] of reference.

In the cases in which adaptive reuse projects are configured as collaborative processes, the internal evaluation that characterizes the decision-making process, defined as "co-evaluation" [38-40], has been conceived as a shared process, built with and for the community [41-43]. In multi-actor processes, 
co-evaluation is also a product of co-operation, a participatory and engagement activity that overturns the ordinary paradigm of one-way evaluation, integrating into the process the interactions among evaluators and stakeholders, experts and non-experts, and communities and citizens.

Co-evaluation, which is more widespread in the areas of teaching [44] and marketing [45], can be configured in complex and adaptive decision-making processes as a systemic application of the evaluation process $[46,47]$ that concerns a common good. It is thus an experiment with the ability of individuals to evaluate together, each with their different skills, to reduce conflicts and bring out shared benefits [40]. Co-operation is a precondition for co-evaluation and enables accountability and mutual learning functions of evaluation in multi-actor settings.

Among the multi-stakeholder collaborative processes, in particular the Living Labs are analyzed. The framework of the Living Lab (LL), typical of the world of open innovation, is identified as a user-centered ecosystem, based on a systemic co-creation approach that integrates research and innovation processes in communities and real-life contexts. Penny Evans, from Bristol Living Lab, describes the LL as "a place where citizens, artists, technologists, companies and public sector organizations can come together to co-create ideas, tools and technologies that will address local challenges; a place for innovation and exploration of new possibilities, where reflection and evaluation are integrated into the work process" [48]. Adopted by the European Union under the impetus of the Finnish Presidency in 2006 with the birth of the European network ENoLL [49], the LL's approach is also encouraged by the European 2020 strategy, with the Horizon 2020 implementation tool, to overcome the model based exclusively on research and technological development, thus promoting a new model aimed at combining scientific research, technological development, and the market.

According to the above perspective, LLs can assume a significant role in the construction of community-driven reuse processes. These processes often manifest themselves starting from concrete experimentation in the territory [50], identifying places of disused $\mathrm{CH}$ and distinguishing in the characterization of LLs an architecture useful for the development of a structured regeneration process that is able to endure and is no longer identifiable as a mere "hopeful monster" [51]. LLs operate as intermediaries between citizens, research organizations, companies, cities, and regions for the co-creation of shared values.

The case study analyzed in this paper is a research-action project applied in the south of Italy, in the city of Salerno, with the aim of structuring and testing a methodological path for the activation of a Living Lab dedicated to the adaptive reuse of $\mathrm{CH}$. In particular, it is a Creative Living Lab that was implemented to experiment with a bottom-up reuse process, in a broader context of culture-led regeneration [52,53], of a former church built in 1530 and located in the historical center of the city, which was deconsecrated and subsequently abandoned in 1980 .

The remainder of the paper is structured as follows: Section 2 includes materials and analyzed methods related to the decision-making structure of a Living Lab process, the deliberative evaluation techniques used to elicit values, and the experimentation of co-evaluation approaches in collaborative processes. Section 3 presents the case study of the San Sebastiano del Monte dei Morti Living Lab (SSMOLL) project, and Section 4 outlines the partial results of the first year of activity. Finally, Section 5 presents the conclusions and perspectives of ongoing research.

\section{Materials and Methods}

The proposal of the methodological approach for adaptive reuse of disused and/or abandoned $\mathrm{CH}$ was articulated considering the following issues:

- The construction of a collaborative decision-making process, through the establishment and activation of a Creative Living Lab;

- The elicitation of values through deliberative evaluation techniques;

- The co-evaluation role within the collaborative decision-making process. 
The following paragraphs describe the three main aspects that characterize the articulation of the methodological approach.

\subsection{The Structuring of a Living Lab for Adaptive Reuse Processes}

Despite numerous implementations at various levels, themes, and scales, the main features of an LL can be outlined as follows [48]: definition of a quadruple helix model for governance and development, consisting of universities, governments, companies, and citizens; identification of the different levels of analysis [54] considering "macro" (organizational), "meso" (project), "micro" (direct involvement actions); adoption of multi-methodological approach, user involvement, multi-stakeholder participation, process setting in a real-life context and co-creation.

The development phases of an LL, summarized in three main steps [48], consider the following:

1. Exploration of the "current state" of the decision-making context and users to design possible "future states";

2. Experimentation, i.e., co-designing in a real-life context to understand the relationships between the context and the users, triggering new possible behaviors and habits;

3. Assessment of impacts by comparing the "current state" and the "future state".

An evolution of the LL model described is represented by the FormIT methodology, developed by researchers at Luleå University of Technology to support user involvement in LLs [55], and then by the Living Lab Network [41].

Therefore, translating the purpose of the LL from the generation and validation of a product to the co-creation of a collaborative decision-making process, from the production of a finished object to the co-production of a process, and from the general "real-life context" to the specific "places of environmental and cultural heritage", a particular application of the LL can be identified as a methodological framework for the activation of a process of adaptive reuse and enhancement of $\mathrm{CH}$, which is flexible according to the context variables that the specific case study requires (Figure 2).

\begin{tabular}{|c|c|c|c|c|}
\hline $\begin{array}{l}\text { Living Lab } \\
\text { standard } \\
\text { approach }\end{array}$ & $\begin{array}{l}\text { Living Lab } \\
\text { Formlt } \\
\text { approach }\end{array}$ & $\begin{array}{c}\text { The Living Lab Network } \\
\text { approach } \\
\text { [FormIT + 4CO model] }\end{array}$ & $\begin{array}{l}\text { CDMP-Living Lab } \\
\text { proposed } \\
\text { approach }\end{array}$ & \\
\hline $\begin{array}{l}\text { scope: } \\
\text { open innovation }\end{array}$ & $\begin{array}{l}\text { scope: } \\
\text { loT innovation }\end{array}$ & $\begin{array}{l}\text { scope: } \\
\text { territory/urban innovation }\end{array}$ & \multicolumn{2}{|l|}{$\begin{array}{l}\text { scope: } \\
\text { adaptive reuse innovation }\end{array}$} \\
\hline 1. Exploration & 0. Planning phase & 0. Co-exploring & \multirow{15}{*}{\multicolumn{2}{|c|}{$\begin{array}{l}\text { 1. CLL Activation } \\
\text { a. planning } \\
\text { b. co-explore } \\
\text { c. tentative co-design } \\
\text { 2. CH re-Open } \\
\text { 3. CLL Actions } \\
\text { a. co-explore } \\
\text { b. co-design } \\
\text { c. co-test } \\
\text { d. co-evaluate } \\
\text { 4. CH Reuse monitoring }\end{array}$}} \\
\hline 2. Experimentation & $\begin{array}{l}\text { 1. Concept design } \\
\text { a. generate needs }\end{array}$ & $\begin{array}{l}\text { 1. Co-design } \\
\text { a. appreciate }\end{array}$ & & \\
\hline \multirow[t]{13}{*}{ 3. Assessment } & $\begin{array}{l}\text { b. design } \\
\text { c. evaluate }\end{array}$ & $\begin{array}{l}\text { opportunities } \\
\text { b. design concepts }\end{array}$ & & \\
\hline & & c. co-evaluate concept & & \\
\hline & 2. Prototype design & 2. Co-production & & \\
\hline & $\begin{array}{l}\text { a. generate needs } \\
\text { b. desian }\end{array}$ & $\begin{array}{l}\text { a. appreciate } \\
\text { opportunities }\end{array}$ & & \\
\hline & c. evaluate & b. design tactical & & \\
\hline & 3. Final system design & c. co-evaluate citizens & & \\
\hline & a. generate needs & experience & & \\
\hline & b. design & 3. Co-decision & & \\
\hline & c. evaluate & 3. co-decision & & \\
\hline & 4. Commercialisation & $\begin{array}{l}\text { a. appreciate } \\
\text { opportunities }\end{array}$ & & \\
\hline & & b. design rules system & & \\
\hline & & $\begin{array}{l}\text { c. co-evaluate } \\
\text { scaling-up experience }\end{array}$ & & \\
\hline & & $\begin{array}{l}\text { 4. Implementation of } \\
\text { co-governance model }\end{array}$ & & \\
\hline
\end{tabular}

Figure 2. A comparison between the different approaches of Living Labs analyzed and the proposed approach. 
In the present case, a variant of the LL approach was structured, and was strongly characterized by the need to make the research process coincide with that of active regeneration in the territory, while simultaneously being engaged in the reopening of the cultural asset (Figure 3).

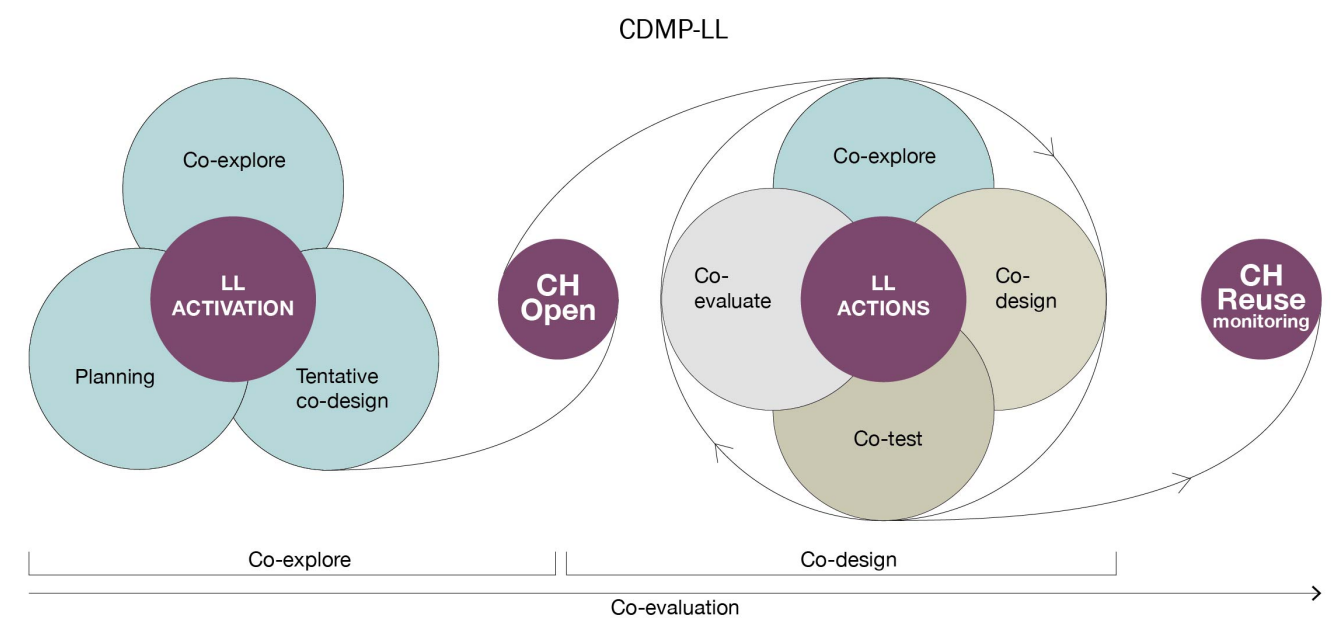

Figure 3. Collaborative Decision-Making Process Living Lab (CDMP-LL): A focus on the methodological proposal for the adaptive reuse of cultural heritage.

The methodological approach proposed identifies four main phases characterizing the research-action process:

1. CLL activation: the goal is to communicate and involve the community in its activation from the beginning of the open process.

2. CH open: the reopening of the abandoned building to the community. This is a real event for the community; this phase highlights that, only after a complex phase of identification of needs and construction of awareness of the values recognized in the $\mathrm{CH}$, is it possible to trigger the conditions for a real change.

3. CLL actions: a co-design phase in which the production of different reuse actions is a decisional opportunity [56] to identify and test possible reuses of the cultural good, revealing shared scenarios and producing, at the same time, new forms of social, cultural, and economic capital in the reference context. Each action is characterized by the phases of co-exploration, co-designing, co-testing, and co-evaluation, to include the community in each phase of the process and evaluate each action.

4. CH reuse monitoring: the evaluation of the individual actions tested allows identification of the preferred reuse solutions able to make the reuse of the good sustainable over time.

Specifically, the CCL activation phase consists of the following steps.

Planning: In this phase, different actions are developed to identify the characteristics of the $\mathrm{CH}$ under examination and to identify the enabling conditions [57], the aim to be pursued, the scales of analysis, the features of the context, and the limits or constraints that may influence the decision-making process to be activated.

Co-explore: A survey of the current state of the $\mathrm{CH}$, the context, and the users directly or potentially interested, to take over objective data and subjective preferences through deliberative evaluation techniques. The aim is to detect the criticalities and the perceived potentials [41], and to identify shared perspectives.

Tentative co-design: Starting from the results obtained in the co-exploration phase, this is a step oriented to the identification of the main characteristics of the CLL through the first action of planning, and the selection of actions able to build a shared collective awareness. 
Co-evaluation: In the methodological process of the experiment, co-evaluation is a transversal action present during every phase of the process. In each phase it is possible to share the results with the other actors involved in the decision-making process, to verify their multi-dimensional components and to express quantitative and qualitative indicators generated by the active collaboration of the community, which is useful for evaluating the impacts of the actions carried out.

\subsection{The Elicitation of Values by Deliberate Valuation Techniques}

The identification and characterization of valuation techniques to elicit the complex values emerging from the processes of adaptive reuse of the $\mathrm{CH}$ are particularly significant in the assessment of the values of both use and non-use of the asset [31,58], and all intrinsic values, understood as "glue values", which are capable of generating new social capital in the patrimonial community around the church. The deliberative valuation techniques include both monetary and non-monetary tools [59-61] that are useful for eliciting the values that characterize the LLs' methodological approach to the adaptive reuse of a cultural good. These techniques can be said to be included in the broader cataloguing of methods defined for the evaluation of Culture Ecosystem Services: those based on revealed preferences and those related to declared preferences [62].

Different techniques have been used to elicit complex values during the adaptive reuse process. Specifically, the choice of techniques varies according to the main phases of the process: co-explore, co-design, and co-evaluate (Figure 4).

\begin{tabular}{|c|c|c|}
\hline $\begin{array}{l}\text { Process } \\
\text { phase }\end{array}$ & Goal & Technique \\
\hline Co-explore & $\begin{array}{l}\text { Participatory analysis of } \\
\text { the territorial context and } \\
\text { the community of } \\
\text { reference, with reference } \\
\text { to the historical asset to } \\
\text { be reactivated }\end{array}$ & $\begin{array}{l}\text { Direct observation } \\
\text { Documentation } \\
\text { Media analysis } \\
\text { Social media analysis } \\
\text { Interviews } \\
\text { Questionnaires } \\
\text { Storytelling } \\
\text { Participatory mapping }\end{array}$ \\
\hline Co-design & $\begin{array}{l}\text { Participatory design: } \\
\text { construction of shared } \\
\text { scenarios and simulation } \\
\text { of possible reuses of } \\
\text { space }\end{array}$ & $\begin{array}{l}\text { Expert-based } \\
\text { Focus group } \\
\text { Q-method } \\
\text { Workshop } \\
\text { Planning for real }\end{array}$ \\
\hline Co-evaluate & $\begin{array}{l}\text { Collaborative evaluation } \\
\text { of both the process } \\
\text { phases and the individual } \\
\text { actions produced }\end{array}$ & $\begin{array}{l}\text { Questionnaires } \\
\text { Interviews } \\
\text { Workshop } \\
\text { Delphi } \\
\text { Ranking } \\
\text { Dot voting }\end{array}$ \\
\hline
\end{tabular}

Figure 4. Non-monetary valuation methods and techniques used in the San Sebastiano del Monte dei Morti Living Lab (SSMOLL) process.

In the co-exploration phases, both interpretive and potentially-interpretative techniques [62-64] were used, based on the methods of revealed preferences and declared preferences. Among these were the following: 
- Direct observation: human action and behavior reflect social value;

- Documentation: the consultation of textual, photographic, and historical materials reveals information on human preferences concerning the issues addressed;

- Media/social media analysis: the analysis of shared material on the theme or place of interest allows us to obtain data related to the reference values.

All of these techniques are interpretative and based on the revealed preferences; they observe behaviors and analyze documents to indirectly determine people's preferences.

Other techniques used in the co-explore phase are built on the declared preferences method as based directly on the statements made by the stakeholders questioned to express a value. Among these, the following potentially-interpretative techniques have been used in the co-exploration phase: interviews; questionnaires; storytelling; participatory mapping [65,66].

In the co-design phases, potentially-interpretive deliberations were used, based on the methods of declared preferences. Among these were the following: expert-based, like the Delphi method [67]; focus group; Q-method [68,69]; planning for real; workshop.

For the co-evaluate phases, mixed and experimental techniques were used, frequently based on the logic of role-playing games. Among these were the Delphi and ranking approaches. The most-used technique to share the evaluation phase with the community was Dot Voting, which is a simple tool used to democratically prioritize items or make decisions in a group setting, to narrow down alternatives, and converge to a set of concepts or ideas.

\subsection{Co-Evaluation in Collaborative Decision-Making Processes}

In the hybrid and collaborative dimension of approaches for the adaptive reuse of $\mathrm{CH}$, the evaluation and articulation of the decision-making process play a strategic role, particularly for those goods whose value, in the absence of a market, is not reflected in traditional economic estimates. The value of these assets can be understood as the expression of complex values [70,71], deriving from structured social planning through the active involvement of informal and/or formal groups that cooperate with the intention to restore to the spaces a value of use, a value independent of use, and an intrinsic value.

In this context, co-evaluation is able to include stakeholders in the whole decision-making process, contributing both to the project and the evaluation phases. Starting from applications in the fields of education and marketing, co-evaluation allows the user to learn from the activities of others and, by developing the ability to discern between positive and negative aspects, to identify ways to improve, increase, and explore individual and collective opportunities. Therefore, co-evaluation can be understood as a tool able to integrate users in the process, thereby empowering them. The citizens thus learn to refine observation and differentiate their perceptions, select the relevant elements and relativize judgements (both their own and others'), and to attribute meaning and value to the actions [72]. In particular, the experiences developed in the field of didactic activities [73] make it possible to test a co-evaluation process to be included in the methodological structure of the CLL, according to the following main steps:

- Development of lists of shared indicators and negotiations between experts and users;

- Individual evaluation of the experience by both experts and users participating in the process, scoring each indicator according to a Likert scale;

- Indicators ranking and comparison between the preferences and contents of the answers, and analyzing the respective attributions of a score;

- Shared indicators verification and, in the case of disagreement, comparison of positions through mutual dialectical observations. 
The interaction that develops between the participants in the decision-making process (centered on the understanding of the reasons related to the choices) makes it possible to overcome the individual expression of judgement by encouraging co-operation and the origin of relational values and shared preferences that are associated with relationships both interpersonal and guided by political and social norms [74]. In this sense, co-evaluation techniques are appropriate tools in complex, interactive, collaborative and incremental decision-making processes, and are particularly significant in assessing the social and cultural impacts generated by actions of adaptive reuse and the enhancement of existing heritage.

\section{The Case Study: The SSMOLL Experiment}

The case study was tested in the historic center of Salerno, in an area particularly dense with ecclesiastical buildings that, over the centuries, have characterized the urban landscape. Fifty-three religious buildings were found in the historical center of Salerno. Of 15 large monasteries, 9 have been reused through the implementation of private functions, hotels, health services, barracks, and school facilities. Of the 38 churches present, 17 are deconsecrated. Specifically, $11.8 \%$ of all of the churches are now in a state of abandonment, 35.3\% are underutilized, and 52.9\% have been converted into associations for cultural activities.

Among the deconsecrated churches in a state of disuse is the former church of San Sebastiano del Monte dei Morti, known as "i Morticelli", built in 1530, and unused since the 1980s (Figure 5). The church, now owned by the municipality, is a former baptistery, located on an axis that acts as a hinge between the southern part of the old town, which is currently dedicated to commercial and tourist activities, and the northern area, which has a purely residential character, with large disused buildings that are far from the main city flows and services.

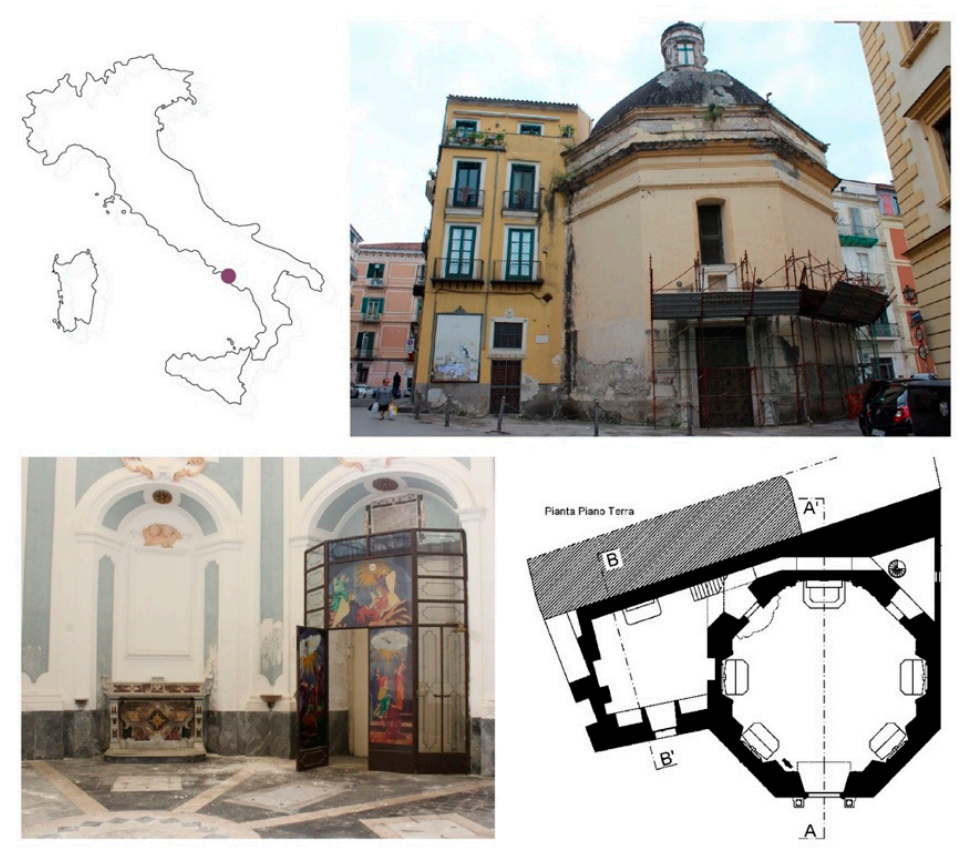

Figure 5. Church of Morticelli, Salerno, Italy.

In the process undertaken to reactivate this cultural asset, the activation of a CLL was tested to verify the opportunity of adaptive reuse of space, within a broader community-driven and culture-led collaborative decision-making process [44,45,75-77]. The project is called the "San Sebastiano del Monte dei Morti Living Lab" (SSMOLL), and was started in March 2018. The implementation of the SSMOLL LL follows the procedure described in Section 2, which outlines the methodology phases according to the interaction with the practice. 


\subsection{Co-Explore}

The planning phase of the process coincides with the setting up of the LL and the activation of the partnership of the quadruple helix [48], in this case, comprised of the Department of Architecture (DiARC) of the University Federico II of Naples, the Municipality of Salerno, and the Blam collective. This collaboration was formally established by a scientific agreement temporarily entrusting the church to the Blam collective to reopen the space and trigger the process of co-operation between all of the actors involved.

In this first phase, the objectives of the process were defined as follows:

- To identify new functions and related values for the use of the $\mathrm{CH}$;

- To build and enhance social and professional networks able to connect people and their territory;

- To activate a more comprehensive process of regeneration of the historical center of Salerno starting from the reuse of the former Morticelli church.

Subsequently, the project scales were defined: micro, concerning the reuse of the former Morticelli church; meso, concerning the construction of a cultural district through the networking of the former churches in the historic center of Salerno; macro, referring to the activation of a process of regeneration of the historic center of Salerno through specific interventions developed and implemented through a bottom-up approach (Figure 6).

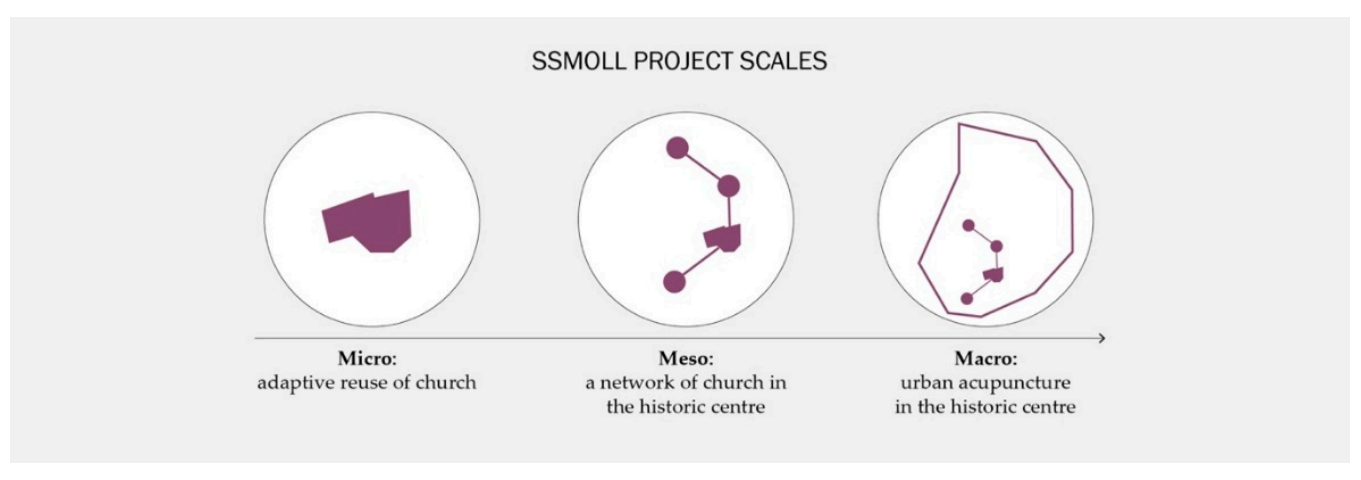

Figure 6. Fields of intervention.

Finally, the analysis of the context, its potential, and its limits, allowed the decision process to be structured and useful actions to be organized for the co-exploration phase.

The months of activities related to opening the church coincided with the phase of co-exploration, which was aimed at investigating the current state, i.e., the analysis of the characteristics of the cultural asset and the urban and social context, the mapping of stakeholders, the construction of territorial partnerships, and the involvement of citizens in the process underway through the implementation of deliberative evaluation techniques (Figure 7).

The first operation was the realization of technological support constituted by a web platform (www.blamteam.com), with the help of social networks (Facebook, Instagram). The web platform and social media made it possible to accompany the implementation of the various interventions with the large repository of voluntarily provided data (interviews, photographs, stories, memories, etc.). In this sense, social media support collaborative decision-making by facilitating public participation in an active, fast, and horizontal manner through digital storytelling [78], which can also be monitored through social media analysis to attempt to investigate the field of social relationships, knowledge systems, and cultural diversity of the community of reference.

Subsequently, through the use of deliberative evaluation techniques based on the detected preferences (direct observation and documentation) and declared preferences (structured online questionnaires, semi-structured video-interviews, and storytelling), qualitative and quantitative data were collected to investigate the relationship between citizens, their territory, and the church. 


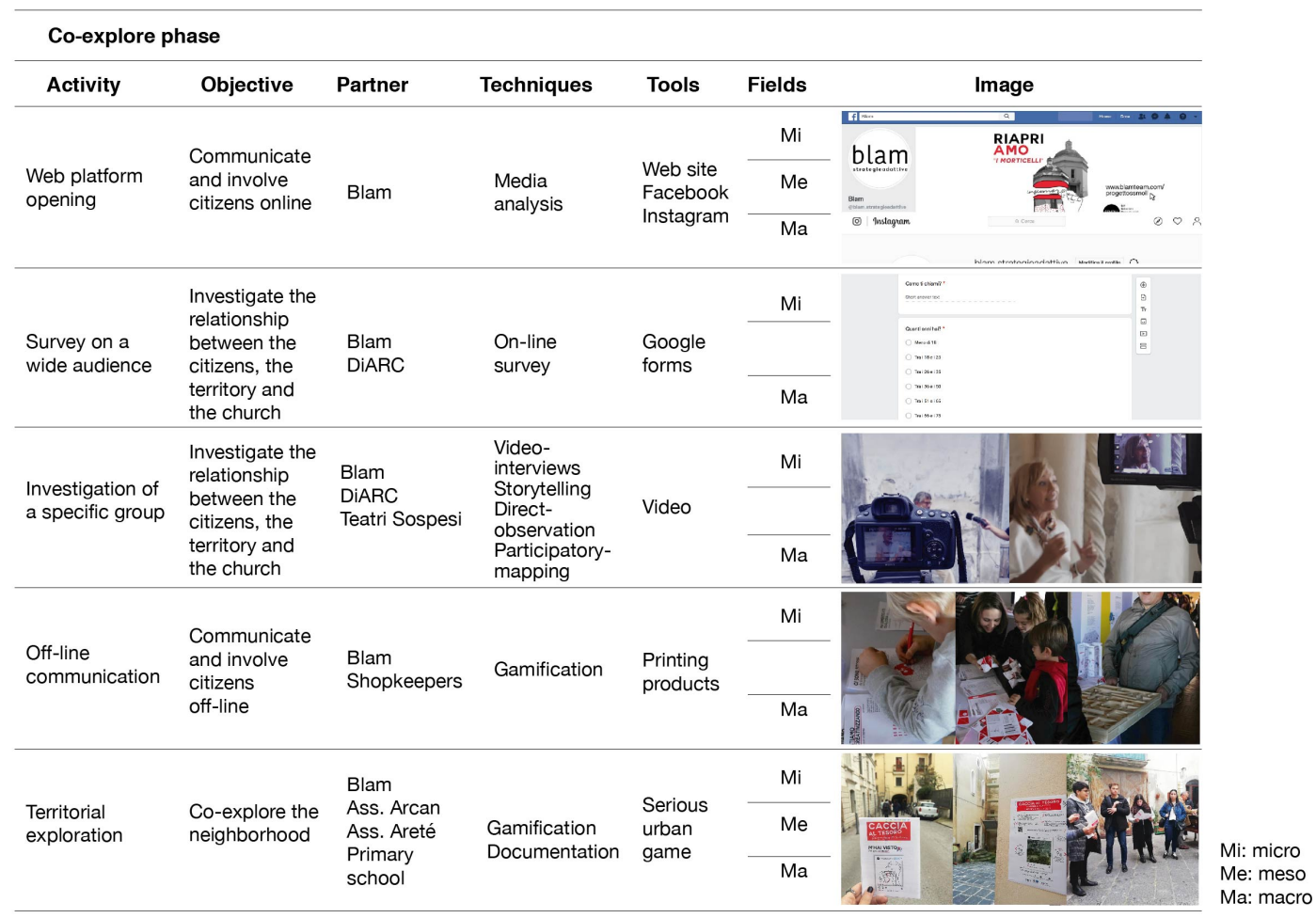

Figure 7. SSMOLL co-explore phase.

In detail, 55 citizens of the historic center of Salerno, aged between 25 and 75 years, including students, employees, local artisans, and retired people, were interviewed. The interviews comprised a total of six questions and were semi-structured into three main sections:

- The relationship with the city of Salerno. Users were asked to define, using the five senses, the potential and criticality of their city;

- The relationship with the former Morticelli church, to gather stories and memories connected to it;

- The visions of a possible reopening and reuse of the church, to identify needs and desires, either latent or explicit.

Online, 200 questionnaires were administered. These were structured with the same articulation as that of the interviews but allowed more space for suggestions for possible reuse of the former church and alternative means of collaboration. The questionnaire was articulated as follows:

- "Let's get to know each other": informal cognitive phase to collect personal data related to the education and origin of citizens according to the city's districts;

- "The Salerno you live in": useful to identify habits and means to frequent the city;

- "Your impressions about Salerno": A qualitative survey phase on the cultural offerings present in the city, to determine the degree of satisfaction of users expressed on a scale from 1 to 5 ;

- "How much do you know the Morticelli": to explore the degree of knowledge about the abandoned space;

- "The idea": A phase in which the user was presented with a set of possible reuses of the historical building to choose from on a scale from 1 to 5 ;

- "How can we collaborate": the last step of the questionnaire focused on the in-depth knowledge of the users, their habits, and their willingness to collaborate by donating time, skills, and money.

To actively involve citizens in the ongoing process and allow them to get to know the former church that is being reactivated, structured communication and knowledge actions on the dynamics of urban gaming were promoted in the territory to stimulate the broadest possible inclusion and 
integration. Specifically, these were as follows: A communication campaign "SSMOLL Bombing", oriented to stimulate interactive, playful activities carried out to obtain useful information about the church and the process underway; a photographic treasure hunt "Have you seen me from this view?", a territorial exploration in the form of a serious urban game $[79,80]$ which transformed the urban context into a playful space of discovery. More than 100 images of the historic center were produced, with more than 2050 preferences expressed through a popular jury system activated on the web.

The time dedicated to the co-exploration phase was necessary also to identify the values associated with the historical and cultural heritage by the citizens. The former religious building is characterized by a high symbolic value, as noted mostly by the people who visited the church before its closure. Nonetheless, the loss of the church's sacred symbols, and its small size and unique octagonal shape, in addition to its central position in the historical center, allowed potential users to imagine new possible uses of the space. Key words were repeated among users when they first entered the former church after its reopening, and in the answers to the questionnaire, to express the feeling transmitted by the Morticelli church: "welcoming" emerged first, followed by "fascinating", and "unexpected".

Following the co-exploration phase, the reopening of the former church made it necessary to reformulate the methodological path outlined previously. The activities carried out in proximity to the event organized for the reopening required a less-structured phase, defined as "tentative co-design". With this term, we mean a deliberately labile and open phase to co-evaluate the results of the co-exploration and to include the changes in the scenario suggested by the community that was progressively created around the Morticelli church.

\subsection{Co-Design}

The reopening of the former church after more than thirty years transformed it into an opportunity space [81], a catalyst of occasions, meetings, visions, and ties, and a generator of new values. Moreover, the reopening allowed self-regeneration of the church's glue values.

From the indicators that emerged during the co-exploration phase, the following thematic clusters were identified as being significant to the selection of the actions to be carried out, and useful to test possible reuses of the former church space (Figure 8): Artistic installations related to contemporary art, ceramics, architecture and photography; concerts; theatre performances; reading; artistic performances; installations; public assemblies and meetings.

The activities produced were assessed using the following:

- The satisfaction index of the participants using a scale from 1 to 5 ;

- The average rate of participation in the individual activities;

- The adaptive capacity of the former church to accommodate the different activities tested, expressed on a scale from 1 to 5 ;

- The willingness to donate and the willingness to pay for each specific activity proposed, expressed on a monetary scale.

Each action was designed as an iterative and collaborative moment of the overall process, including the following phases:

- Co-exploration, in which the participants (students, artists, residents, etc.) co-produce material of knowledge about the Morticelli church and the surrounding urban fabric through interviews, video-interviews, urban explorations, and brainstorming;

- Co-design, in which all the participants, guided by the Blam collective in moments open to citizens, co-create and co-test possible reuse solutions;

- Co-evaluation, in which the participants give back to the whole community through the work produced on the occasion, through events and meetings, thus stimulating feedback and reactions, and activating modes of interaction through collaborative evaluation.

In cases in which it was not possible to implement the elaboration of an indicator's ranking that was shared and negotiated between experts and users, a phase of individual experience evaluation 
was undertaken by both experts and participants. This phase was followed by the comparison of the responses and feedback obtained, to carry out a self-evaluation of the experience, to explain its potential and criticality, and to verify its replicability.

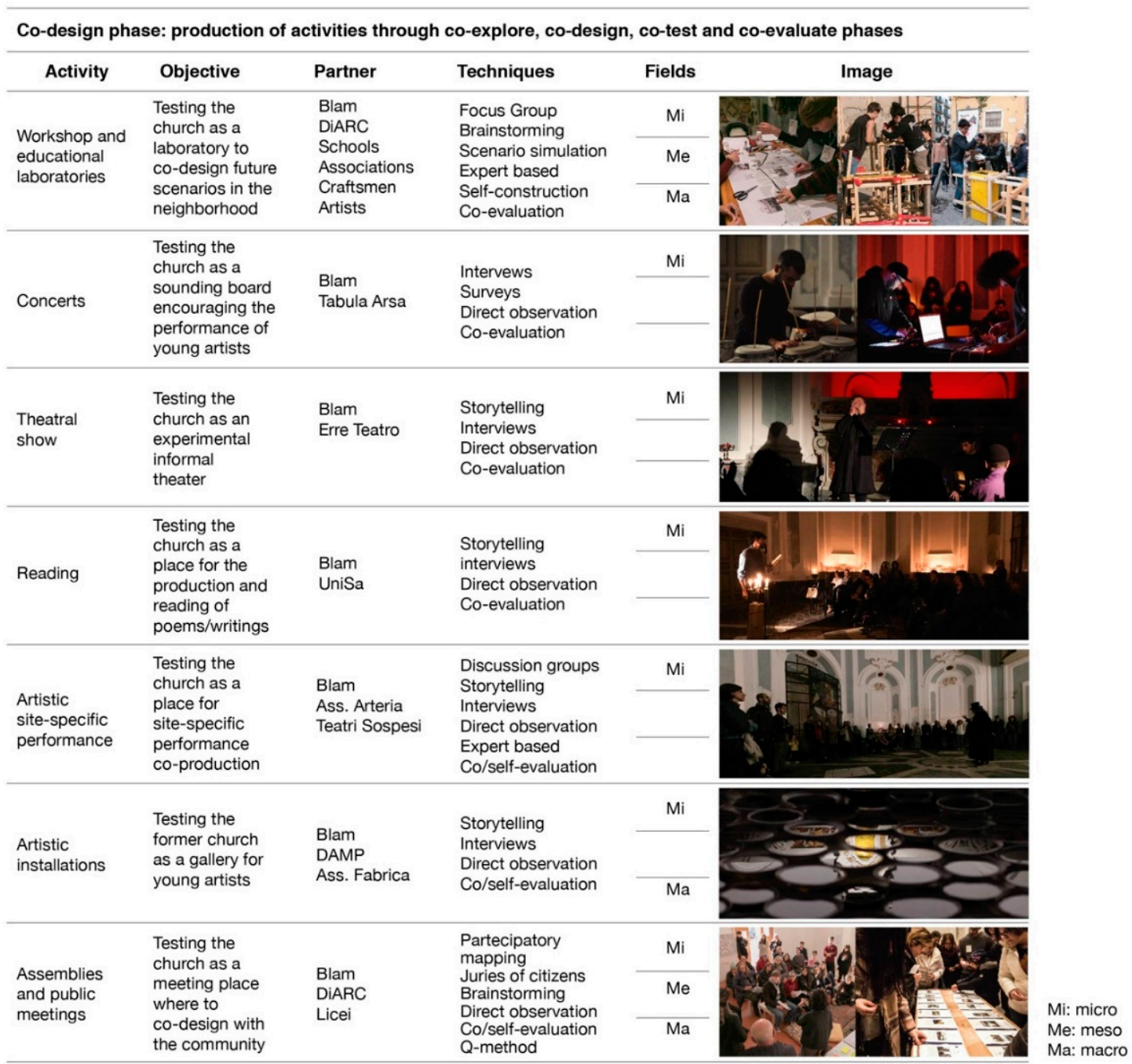

Figure 8. SSMOLL co-design phase.

\section{Results}

The methodological process of the experiment to activate a CCL for the adaptive reuse of the former Morticelli church is still in progress. The relationship of constant interaction between research and action has allowed the initially structured methodological approach to be redefined and experimentation with an adaptive collaborative decision-making process to activate and generate new value chains [82-87].

The questionnaire distributed before the reopening of the Morticelli church involved more than 200 users, of which $47.7 \%$ were in the $26-35$ age group, $62 \%$ were women, and $62.5 \%$ were graduates. The historical center was one of the most frequented places in Salerno by the participants in the survey, and $56.6 \%$ of these claimed to participate in cultural initiatives in the historical center rarely (once per month) due to the quality of the proposals offered and the scarce availability of public transport. More importantly, $47.7 \%$ of citizens were dissatisfied with the cultural offering. More than $80 \%$ of the participants in the activities organized within the CLL identified the cultural sector (in particular concerts and exhibitions) as the key to success in promoting a process of redevelopment of the urban and social context of Salerno. 
Concerning the former Morticelli church, via the surveys, the values that users recognize in the historical building (before its reopening) were also investigated, based on the Cultural Ecosystem Services (ecosystems and human well-being: current state and trends) classification. The central values that were recognized were the historical and cultural values, followed by the aesthetic and social values. Ninety-six percent of the interviewees and respondents to the questionnaire did not know the name of the church or had never visited it. Nevertheless, $97.6 \%$ of people were curious to see and to know the space, wishing to use it for exhibitions and art shows (25\%), workshops (21.2\%), neighborhood meetings $(17.1 \%)$, and concerts $(14.5 \%)$, with activities to be held at least once a week $(65.9 \%)$.

The emerging needs in the first phase of co-exploration led to the choice to characterize the LL for adaptive reuse of the divested asset with a creative and cultural meaning (CLL).

After the first year of activity, the former Morticelli church hosted more than 3000 visitors, carrying out cultural and creative activities for more than $1000 \mathrm{~h}$. More than 32 cultural and social activities were carried out, dedicating over $150 \mathrm{~h}$ to workshops and training activities, thereby multiplying the opportunities for cultural encounters for residents involved in co-exploration and co-design. In particular, the site-specific performances were the most attractive because the high participation rate was also supported by a medium-high willingness to donate and pay. The theatrical performances designed and realized for the church of Morticelli were very successful with a high percentage of approval (Figure 9).

\begin{tabular}{lcccc}
\hline \multicolumn{1}{|c}{ Action clusters } & $\begin{array}{c}\text { Average } \\
\text { participation of } \\
\text { people/event (No.) }\end{array}$ & $\begin{array}{c}\text { Average } \\
\text { satisfaction } \\
\text { index (1 to 5) }\end{array}$ & $\begin{array}{c}\text { Adaptive } \\
\text { space capacity } \\
\text { (1 to 5) }\end{array}$ & $\begin{array}{c}\text { Willingness to } \\
\text { pay/donate } \\
\text { (average in €/event) }\end{array}$ \\
\hline Workshop and lab & 32 & 4 & 3 & $15 €$ \\
\hline Concert & 42 & 3 & 2 & $10 €$ \\
\hline Theatre performance & 38 & 4 & 4 & $8 €$ \\
\hline Reading & 29 & 2 & 2 & $6 €$ \\
\hline $\begin{array}{l}\text { Site-specific } \\
\text { artistic performance }\end{array}$ & 54 & 5 & 5 & $12 €$ \\
\hline Installation & 46 & 4 & 5 & $8 €$ \\
\hline Public meeting & 28 & 5 & 4 & $/$ \\
\hline
\end{tabular}

Figure 9. SSMOLL activities evaluation matrix.

All of the activities carried out involved participants aged between 6 and 78 years, with the highest participation rate being in the $28-48$ age group. The SSMOLL CLL extended the collaboration network to the following: educational institutions; cultural institutions; commercial activities; foundations, banks, and clubs, both local and national; professionals, including local and national artists and artisans, architects, photographers, and video-makers; non-profit associations and committees in the area; and volunteers.

The relationships triggered by the formation of the LL were thus analyzed by type, quantity and density of the bond developed over time. To this end, the collaborations were divided into single, sporadic, and periodic, and articulated in three main stages during the period of activity of the CLL (Figure 10). 


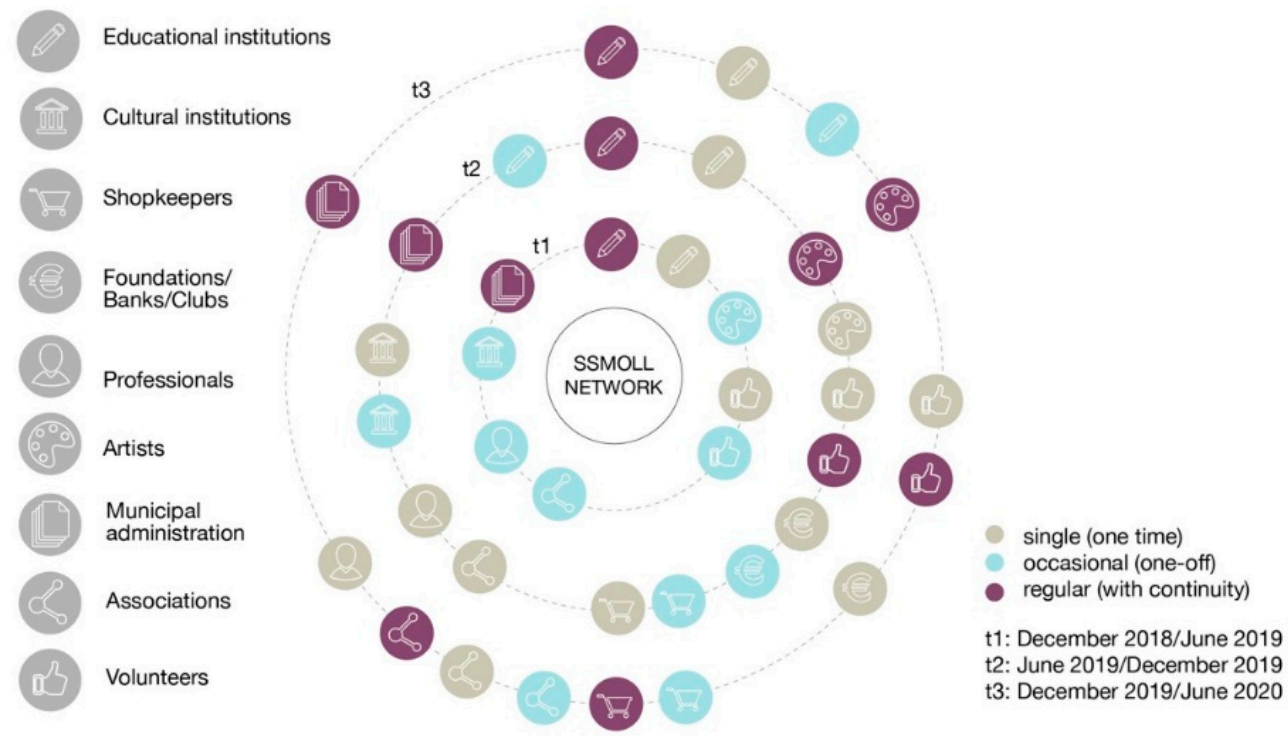

Figure 10. SSMOLL collaboration system activated over time.

The strong territorial connotation was proven to be a fundamental characteristic that is capable of attracting local funding. In the economic and cultural development of the territory to which it belongs, this provides concrete opportunities for achieving its investment objectives in a "global" perspective, consistent with Sustainable Development Goals (SDGs) 7, 9, 11 and 15. For these goals, the new regeneration processes are considered to be capable of configuring transversal interconnections between urban and territorial heritage. In this sense, the activation of the CLL has made a historical-cultural heritage site accessible and put it at the center of an autopoietic process of generating intrinsic values capable of determining social, cultural, and economic impacts over time.

Indeed, adaptive reuse is configured as an implementation tool of SDGs 7 and 11, which favor the passage from the vision of cultural heritage as an asset to be preserved, to capital to be valorized and reused through the involvement of the community. Thus, it is able to influence social interaction and change attitudes, lifestyle, and behavior [88].

The first year of the SSMOLL project has also seen the formation of a team of regenerators (under 35) that, within the CLL, has constituted work experience that remains in progress. This team has generated about EUR 35,000 from crowdfunding operations, donations for events, prizes for won tenders, and donations from associations, banks, and banking foundations. The contributions of volunteers, professionals, artists, and those who have chosen to donate time and experience to the project have not been estimated.

\section{Discussion}

The tested methodological approach was built around the idea that a process of adaptive reuse of $\mathrm{CH}$ through the implementation of a Living Lab can not only aim at identifying a new function by evaluating possible scenarios and outcomes, but can itself generate new values during the path of reuse, with repercussions for the entire urban context. The user-centric characteristic of the Living Lab allows a significant transformation of the urban stakeholders from users to actors in the process of re-appropriation and co-management of the asset, primarily encouraging the co-production of new values. The deliberative techniques used in the co-exploration and co-design phases were proven to be effective not only in finding useful project indicators, but also in communicating and involving the community in each phase of the process. Therefore, it may be useful to expand the potentially deliberate techniques based on the stated preference method, such as Participatory Geography Information System (PGIS), Public Participation GIS (PPGIS), or scenario simulation. The use of technological tools could facilitate and simplify data collection. 
To monitor the activated actions in the experiment of the adaptive reuse of the cultural asset, the range of quantitative and qualitative indicators defined should be increased. For example, the indicators needed to evaluate the social, cultural, environmental, and economic impacts on the community and the territory of reference were missing in this study. Specifically, it is not always possible to co-evaluate all of the actions carried out within the asset; however, it would be appropriate to identify, prior to the activation of the "CLL Actions" phase, the shared criteria with stakeholders involved in the co-evaluation of the outcomes of the tested actions. Generally, the outcome of the co-evaluation feeds the autopoietic process, thereby generating new values related to the cultural asset and the social capital linked to it. This research aimed to develop techniques and modalities of co-evaluation to support adaptive community-based reuse processes.

Finally, results of the analysis of the relationships activated thus far by the SSMOLL Living Lab suggest that much remains to be done. This includes evaluation of the impacts that individual stakeholders have contributed or introduced in the process of adaptive reuse, not only in economic terms. In particular, it would be of interest to assess the related capabilities to collaborate and cooperate to activate productive synergies, and to share human resources and materials in the process of realizing the different actions.

After the first year of the SSMOLL CLL activity, it was evident how the uniqueness of the production and realization of cultural and creative activities in an abandoned building contributes to connecting the user to the territory through an identity process. It is equally evident that the individual actions of the CLL are to be understood not as the aims of the experimental reuse of a building, but as instruments to involve and transform users into actors of regenerative urban processes, in which co-evaluation also becomes a tool for information, education and mutual learning.

\section{Conclusions}

The CLL allowed an adaptive collaborative decision-making process to be structured and tested for the adaptive reuse of the former Morticelli church, which required a considerable commitment to be shared between the different promoters in the diverse phases of the SSMOLL project. It also allowed a heritage community to be generated, ensuring the support of a structured governance to coordinate and manage the different activities. Moreover, the CLL allowed the historical-cultural heritage to be accessible and put it at the center of an autopoietic process of generating intrinsic values that are capable of determining social, cultural, and economic impacts.

The multiplicity of actions developed in the space of the former church over the year is one of the main sources of attraction of the asset, because it consistently represents the hybrid and dynamic vocation of a place in the transition to a new form of use in which all, through the CLL, can become co-actors.

From this first analysis of the results achieved, it can be seen how cultural production in the adaptive reuse of a historical building is significant if planned according to tailor-made logic. The uniqueness of the production and realization of cultural and creative activities contributes to binding the user to the place through an identity path, increasing users' degree of involvement and willingness to donate or pay. In these collaborative processes, the willingness of communities to not only to pay for cultural services, but also to donate their own economic and time resources, and, above all, to cooperate in actions of valorization of the places of their territory, are important for a co-production of new values, relevant for the whole community and future generations.

The research process intends to restart from these considerations to investigate the transformative capacity of glue values to generate different modalities of co-operation, and to support and expand inclusive productivity.

Author Contributions: Conceptualization, M.C., L.L.R. and A.E.; methodology, M.C.; validation, M.C.; formal analysis, L.L.R. and A.E.; investigation, L.L.R. and A.E.; writing—original draft preparation, M.C., L.L.R. and A.E.; writing-review and editing, M.C., L.L.R. and A.E.; visualization, L.L.R.; supervision, M.C. All authors have read and agreed to the published version of the manuscript. 
Funding: This research received no external funding.

Acknowledgments: The authors would like to express thanks for suggestions and critical comments received from the three anonymous referees, which allowed us to improve and integrate them into the paper and to achieve a more significant final result.

Conflicts of Interest: The authors declare no conflict of interest.

\section{References}

1. Guterres, A. Report of the Secretary-General on SDG Progress 2019; United Nations: New York, NY, USA, 2019.

2. UECOSOSC. Special Edition: Progress Towards the Sustainable Development Goals; Publication E/2019/68; United Nations Economic and Social Council: New York, NY, USA, 2019.

3. UNESCO. The UNESCO Recommendation on the Historic Urban Landscape; UNESCO: Paris, France, 2019.

4. Potts, A. The Position of Cultural Heritage in the New Urban Agenda a Preliminary Analysis Prepared for ICOMOS; ICOMOS: Charenton-le-Pont, France, 2016.

5. Council of Europe. Council of Europe Framework Convention on the Value of Cultural Heritage for Society; Council of Europe Publ.: Faro, Portugal, 2005.

6. Grossi, E.; Blessi, G.T.; Sacco, P.L.; Buscema, M. The interaction between culture, health and psychological well-being: Data mining from the Italian culture and well-being project. J. Happiness Stud. 2011, 13, 129-148. [CrossRef]

7. Papacostas, S. Special eurobarometer: European knowledge on economical indicators. In Statistics, Knowledge and Policy 2007: Measuring and Fostering the Progress of Societies; OECD: Paris, France, 2008; pp. 177-196, ISBN 978-92-64-04323-7.

8. Bullen, P.A.; Love, P.E.D. Adaptive reuse of heritage buildings. In Structural Survey; Emerald Group Publishing Limited: Perth, Australia, 2011; Volume 29, pp. 411-421.

9. Bromley, R.D.F.; Tallon, A.R.; Thomas, C.J. City centre regeneration through residential development: Contributing to sustainability. Urban Stud. 2005, 42, 2407-2429. [CrossRef]

10. Cantell, S.F. The Adaptive Reuse of Historic Industrial Buildings: Regulation Barriers, Best Practices and Case Studies; Virginia Tech: Blacksburg, VG, USA, 2005.

11. Latham, D. Creative Re-use of Buildings. Volume 1: Principles and Practice; Donhead Publishing: Dorset, UK, 2000.

12. Conejos, S.; Langston, C.; Smith, J. Designing for Future Building: Adaptive Reuse as a Strategy for Carbon Neutral Cities. Int. J. Clim. Chang. Impacts Responses 2012, 3, 33-52. [CrossRef]

13. Kincaid, D. Adapting Buildings for Changing Uses: Guidelines for Change of Use Refurbishment; Spon Press: London, UK; New York, NY, USA, 2002; ISBN 9789419235705.

14. Wang, H.-J.; Zeng, Z.-T. A multi-objective decision-making process for reuse selection of historic buildings. Expert Syst. Appl. 2010, 37, 1241-1249. [CrossRef]

15. Pickard, R. Management strategies for historic towns in Europe. In Urban Heritage, Development and Sustainability: International Frameworks, National and local Governance; Routledge: New York, NY, USA, 2015; pp. 151-174.

16. Vahtikari, T. Valuing World Heritage Cities; Routledge: Oxford, UK; New York, NY, USA, 2017; ISBN 1317002598.

17. Sonkoly, G.; Vahtikari, T. Innovation in Cultural Heritage: For an Integrated European Research Policy; European Commission Publications Office: Luxembourg, 2018; ISBN 9279780190.

18. Micelli, E.; Pellegrini, P. Wasting heritage. The slow abandonment of the Italian Historic Centers. J. Cult. Herit. 2018, 31, 180-188. [CrossRef]

19. Klamer, A. The values of cultural heritage. In Handbook on the Economics of Cultural Heritage; Ilde, R., Anna, M., Eds.; Edward Elgar Publishing: Cheltenham, UK, 2013; pp. 421-437, ISBN 9780857930996.

20. Klamer, A.; Mignosa, A.; Lyudmila, L. Cultural heritage policies: A comparative perspective. In Handbook on the Economics of Cultural Heritage; Rizzo, I., Mignosa, A., Eds.; Edward Elgar Publishing: Cheltenham, UK, 2013; pp. 37-86, ISBN 9780857930996.

21. MacArthur, E. Towards the Circular Economy, Economic and Business Rationale for an Accelerated Transition; Ellen MacArthur Foundation: Cowes, UK, 2013.

22. Ellen MacArthur Foundation and McKinsey Center for Business and Environment. Growth within: A Circular Economy Vision for a Competitive Europe; Ellen MacArthur Foundation and McKinsey Center for Business and Environment: Cowes, UK, 2015. 
23. Wijkman, A.; Skånberg, K. The Circular Economy and Benefits for Society; Club of Rome: Winterthur, Switzerland, 2015.

24. Ghisellini, P.; Cialani, C.; Ulgiati, S. A review on circular economy: The expected transition to a balanced interplay of environmental and economic systems. J. Clean. Prod. 2016, 114, 11-32. [CrossRef]

25. Lo Faro, A.; Miceli, A. Sustainable Strategies for the Adaptive Reuse of Religious Heritage: A Social Opportunity. Buildings 2019, 9, 211. [CrossRef]

26. Altraeconomia. Available online: https://altreconomia.it/rigenerazione-partecipata-chiese/ (accessed on 19 August 2020).

27. Lindblad, H.; Löfgren, E. Religious Buildings in Transition. An International Comparison; University of Gothenburg: Gotheburg, Sweden, 2016.

28. FRH Europe. Available online: https:/www.frh-europe.org/cms/wp-content/uploads/2017/11/2014-06Secular-Europe-backs-religious-heritage-report.pdf (accessed on 2 October 2020).

29. Sterken, S.; Longhi, A.; De Wildt, K. Decommissioning and Reuse of Churches: Research perspectives and challenges. In Dio Non Abita Più Qui? Dismissione di Luoghi di Culto e Gestione Integrata dei Beni Culturali Ecclesiastici; Innocenti Furina, V., Ed.; Artemide Edizione: Rome, Italy, 2019; pp. 291-307, ISBN 978-88-7575-328-3.

30. Fusco Girard, L. Risorse Architettoniche e Culturali: Valutazioni e Strategie di Conservazione; Franco Angeli: Milano, Italy, 1987. (In Italian)

31. Fusco Girard, L.; Nijkamp, P. Le Valutazioni per lo Sviluppo Sostenibile della Città e del Territorio; Franco Angeli: Milano, Italy, 1997; Volume 74, ISBN 8846401824. (In Italian)

32. Cerreta, M.; Concilio, G.; Monno, V. Making Strategies in Spatial Planning: Knowledge and Values; Springer Science \& Business Media: Berlin/Heidelberg, Germany, 2010; Volume 9, ISBN 9048131065.

33. Cerreta, M.; Giovene di Girasole, E. Towards Heritage Community Assessment: Indicators Proposal for the Self-Evaluation in Faro Convention Network Process. Sustainabilty 2020, 12, 9862. [CrossRef]

34. Cerreta, M.; Panaro, S.; Cannatella, D. Multidimensional spatial decision-making process: Local shared values in action. In Proceedings of the $12 \mathrm{TH}$ International Conference on Computational Science and Its Applications, ICCSA 2012, Lecture Notes in Computer Science (LNCS), Part II, Salvador de Bahia, Brasil, 18-21 June 2012; pp. 54-70.

35. Zeleny, M. What is autopoiesis. In Autopoiesis: A Theory of Living Organization; Elsevier: New York, NY, USA, 1981.

36. Misırlısoy, D.; Günçe, K. Adaptive reuse strategies for heritage buildings: A holistic approach. Sustain. Cities Soc. 2016, 26, 91-98. [CrossRef]

37. Günçe, K.; Misirlisoy, D. Adaptive reuse of military establishments as museums: Conservation vs. museography. WIT Trans. Built Environ. 2014, 143, 125-136. [CrossRef]

38. Guba, E.G.; Lincoln, Y.S. Fourth Generation Evaluation; SAGE Publications, Inc.: Newbury Park, CA, USA, 1989.

39. House, E.R.; Howe, K.R. Deliberative democratic evaluation in practice. In Evaluation Models; Springer: Berlin/Heidelberg, Germany, 2000; pp. 409-421.

40. Van Der Meer, F.-B.; Edelenbos, J. Evaluation in multi-actor policy processes: Accountability, learning and co-operation. Evaluation 2006, 12, 201-218. [CrossRef]

41. Cerreta, M.; Panaro, S. From perceived values to shared values: A multi-stakeholder spatial decision analysis (M-SSDA) for resilient landscapes. Sustainability 2017, 9, 1113. [CrossRef]

42. Zamagni, S.; Venturi, P.; Rago, S. Valutare l'impatto sociale. La questione della misurazione nelle imprese sociali. Impresa Soc. 2015, 6, 77-97.

43. Panaro, S. Landscape Co-Evaluation. Approcci Valutativi Adattivi per la Cocreatività Territoriale e l'innovazione Locale. Ph.D. Thesis, University of Naples Federico II, Naples, Italy, 2015.

44. Dochy, F.; Segers, M.; Sluijsmans, D. The use of self-, peer and co-assessment in higher education: A review. Stud. High. Educ. 1999, 24, 331-350. [CrossRef]

45. Núñez-Barriopedro, E.; Cuesta-Valiño, P.; Penelas-Leguía, A. Co-evaluation, hetero-evaluation and self-evaluation in the area of marketing and market research. In Proceedings of the Edulearn 18: 10th International Conference on Education and New Learning Technology, Palma, Spain, 2-4 July 2018; pp. 3443-3448.

46. Tessaro, F. La valutazione dei Processi Formativi; Armando Editore: Rome, Italy, 1997; ISBN 8871447069. 
47. Borri, D.; Concilio, G.; Selicato, F.; Torre, C. Ethical and Moral Reasoning and Dilemmas in Evaluation Processes-Perspectives for Intelligent Agents 1: Accounting for Non-Market Values in Planning Evaluation. In Beyond Benefit Cost Analysis; Routledge: England, UK, 2017; pp. 249-273.

48. Evans, P.; Schuurman, D.; Ståhlbröst, A.; Vervoort, K. Living Lab methodology handbook. Zenodo 2017. [CrossRef]

49. ENoLL and ENoLL members. Introducing Enoll and Its Living Lab Community; Garcia Robles, A., Hirvikoski, T., Schuurman, D., Stokes, L., Eds.; ENoLL: Bruxelles, Belgium, 2016.

50. Dell'Era, C.; Landoni, P. Living Lab: A methodology between user-centred design and participatory design. Creat. Innov. Manag. 2014, 23, 137-154. [CrossRef]

51. Manzini, E. The new way of the future: Small, local, open and connected. Soc. Sp. 2011, 75, 100-105.

52. Evans, G. Cultural Planning: An Urban Renaissance? Routledge: New York, NY, USA, 2002; ISBN 1134622481.

53. Evans, G. Measure for measure: Evaluating the evidence of culture's contribution to regeneration. Urban Stud. 2005, 42, 959-983. [CrossRef]

54. Ballon, P.; Schuurman, D. Living labs: Concepts, tools and cases. Info 2015, 17. [CrossRef]

55. Bergvall-Kåreborn, B.; Eriksson, C.I.; Ståhlbröst, A.; Svensson, J. A milieu for innovation: Defining living labs. In Proceedings of the ISPIM Innovation Symposium, New York, NY, USA, 6-9 December 2009.

56. Keeney, R. Value-focused thinking: A path to creative decisionmaking. Long Range Plann. 1996, $2,314$.

57. Concilio, G.; Tosoni, I. Innovation Capacity and the City: The Enabling Role of Design; Springer Nature: Cham, Swizerland, 2019; ISBN 978-3-030-00122-3.

58. Turner, R.K. Speculations on Weak and Strong Sustainability; CSERGE: London, UK, 1992.

59. Proctor, W.; Drechsler, M. Deliberative multicriteria evaluation. Environ. Plan. C Gov. Policy 2006, 24, 169-190. [CrossRef]

60. Hirons, M.; Comberti, C.; Dunford, R. Valuing cultural ecosystem services. Annu. Rev. Environ. Resour. 2016, 41, 545-574. [CrossRef]

61. Christie, M.; Fazey, I.; Cooper, R.; Hyde, T.; Kenter, J.O. An evaluation of monetary and non-monetary techniques for assessing the importance of biodiversity and ecosystem services to people in countries with developing economies. Ecol. Econ. 2012, 83, 67-78. [CrossRef]

62. Cheng, X.; Van Damme, S.; Li, L.; Uyttenhove, P. Evaluation of cultural ecosystem services: A review of methods. Ecosyst. Serv. 2019, 37, 100925. [CrossRef]

63. Kenter, J.O.; O’Brien, L.; Hockley, N.; Ravenscroft, N.; Fazey, I.; Irvine, K.N.; Reed, M.S.; Christie, M.; Brady, E.; Bryce, R. What are shared and social values of ecosystems? Ecol. Econ. 2015, 111, 86-99. [CrossRef]

64. Cerreta, M. Cultural, Creative, Community Hub: Dai valori condivisi ai valori sociali condivisi per la rigenerazione della città storica. In Abitare il Futuro; CLEAN: Napoli, Italy, 2016; pp. 134-146.

65. Brown, G.; Raymond, C. The relationship between place attachment and landscape values: Toward mapping place attachment. Appl. Geogr. 2007, 27, 89-111. [CrossRef]

66. Dramstad, W.E.; Tveit, M.S.; Fjellstad, W.J.; Fry, G.L.A. Relationships between visual landscape preferences and map-based indicators of landscape structure. Landsc. Urban Plan. 2006, 78, 465-474. [CrossRef]

67. Nahuelhual, L.; Carmona, A.; Lozada, P.; Jaramillo, A.; Aguayo, M. Mapping recreation and ecotourism as a cultural ecosystem service: An application at the local level in Southern Chile. Appl. Geogr. 2013, 40, 71-82. [CrossRef]

68. Winkler, K.J.; Nicholas, K.A. More than wine: Cultural ecosystem services in vineyard landscapes in England and California. Ecol. Econ. 2016, 124, 86-98. [CrossRef]

69. Pike, K.L. Language in Relation to a Unified Theory of the Structure of Human Behavior; Mouton \& Co.: The Hague, The Netherlands, 1954; ISBN 3111657159.

70. Fusco Girard, L. Creative evaluations for a human sustainable planning. In Making Strategies in Spatial Planning; Springer: Berlin/Heidelberg, Germany, 2010; pp. 305-327.

71. Cerreta, M.; Poli, G. A complex values map of marginal urban landscapes: An experiment in Naples (Italy). Int. J. Agric. Environ. Inf. Syst. 2013, 4, 41-62. [CrossRef]

72. Tessaro, F. Modelli e Pratiche di Valutazione: Dall'osservazione alla Verifica. Lab. Univ. RED-SSIS Veneto 2005. Available online: http//www.univirtual.it/red/files/file/TessaroModelliPraticheValutaz.pdf (accessed on 21 June 2016).

73. Tessaro, F. I fondamenti della valutazione scolastica. Lab. Univ. RED-SSIS Veneto AA 2004, 2005, 1. 
74. Chan, K.M.A.; Balvanera, P.; Benessaiah, K.; Chapman, M.; Díaz, S.; Gómez-Baggethun, E.; Gould, R.; Hannahs, N.; Jax, K.; Klain, S. Opinion: Why protect nature? Rethinking values and the environment. Proc. Natl. Acad. Sci. USA 2016, 113, 1462-1465. [CrossRef]

75. Sacco, P.L.; Zamagni, S. Teoria Economica e Relazioni Interpersonali; Il Mulino: Bologna, Italy, 2006; ISBN 8815114327.

76. Ferilli, G.; Sacco, P.L.; Tavano Blessi, G.; Forbici, S. Power to the people: When culture works as a social catalyst in urban regeneration processes (and when it does not). Eur. Plan. Stud. 2017, 25, 241-258. [CrossRef]

77. Ferilli, G.; Sacco, P.L.; Tavano Blessi, G. Cities as creative hubs: From the instrumental to the functional value of culture-led local development. In Sustainable City and Creativity: Promoting Creative Urban Initiatives; Ashgate: Farnham, UK, 2012; pp. 245-270.

78. Latonero, M.; Shklovski, I. Emergency management, Twitter, and social media evangelism. Int. J. Inf. Syst. Cris. Response Manag. 2011, 3, 1-16. [CrossRef]

79. Coppock, P.J.; Ferri, G. Serious urban games: From play in the city to play for the city. In Media and the City: Urbanism, Technology and Communication; Cambridge Scholars Publishing: Newcastle, UK, 2013; pp. 120-134.

80. McGonigal, J. Reality is Broken: Why Games Make Us Better and How They Can Change the World; Penguin Books: New York, NY, USA, 2011; ISBN 1101475498.

81. Cerreta, M.; Reitano, M. Community-led processes for peri-urban regeneration in Naples: Evaluating scenarios of social self-organisation and cooperation. BDC Boll. Del Cent. Calza Bini. 2019, 19, 167-183. [CrossRef]

82. Cerreta, M.; Diappi, L. Adaptive Evaluations in Complex Contexts: Introduction. Sci. Reg. 2014, 1, 5-22. [CrossRef]

83. Della Spina, L. Adaptive sustainable reuse for cultural heritage: A multiple criteria decision aiding approach supporting urban development processes. Sustainability 2020, 12, 1363. [CrossRef]

84. Giuffrida, S.; Gagliano, F.; Giannitrapani, E.; Marisca, C.; Napoli, G.; Trovato, M.R. Promoting Research and Landscape Experience in the Management of the Archaeological Networks. A Project-Valuation Experiment in Italy. Sustainability 2020, 12, 4022. [CrossRef]

85. Bottero, M.; D'Alpaos, C.; Marello, A. An Application of the A'WOT Analysis for the Management of Cultural Heritage Assets: The Case of the Historical Farmhouses in the Aglié Castl (Turin). Sustainability 2020, 12, 1071. [CrossRef]

86. Forte, F.; Del Giudice, V.; De Paola, P.; Troisi, F. Valuation of the Vocationality of Cultural Heritage: The Vesuvian Villas. Sustainability 2020, 12, 943. [CrossRef]

87. Daldanise, G. From Place-Branding to Community-Branding: A Collaborative Decision-Making Process for Cultural Heritage Enhancement. Sustainability 2020, 12, 399. [CrossRef]

88. Zamagni, S. I luoghi dell'economia civile per lo sviluppo sostenibile. In Da Spazi a Luoghi. Proposte per una Nuova Ecologia dello Sviluppo; AICCON: Forlì, Italia, 2017; pp. 11-20.

Publisher's Note: MDPI stays neutral with regard to jurisdictional claims in published maps and institutional affiliations.

(C) 2020 by the authors. Licensee MDPI, Basel, Switzerland. This article is an open access article distributed under the terms and conditions of the Creative Commons Attribution (CC BY) license (http://creativecommons.org/licenses/by/4.0/). 